\title{
Intrinsic and Extrinsic Factors Influencing Properties and Growth Patterns of Identified Leech Neurons in Culture
}

\author{
Susan E. Acklin and J. G. Nicholls \\ Department of Pharmacology, Biocenter/University of Basel, $\mathrm{CH}-4056$ Basel, Switzerland
}

An analysis has been made of intrinsic mechanisms influencing growth patterns of 2 identified leech interneurons in tissue culture. These small cells (known as DL and VL) display unusual arborizations in the ganglion. The distinctive branching patterns resemble the letter " $T$ " for $V L$ and the letter " $Y$ " for DL. DL and VL cells contain serotonin and can be identified in situ with Neutral red.

1. DL and VL cells were isolated and cultured on 2 homogeneous substrates, concanavalin A (Con A) and leech extracellular matrix extract (ECM). Individual $D L$ and VL cells in culture retained their ability to fire in spontaneous, rhythmical bursts. The synaptic connections formed in culture were specific and differed from those made by other serotonergic neurons.

2. On both Con $A$ and ECM the neurons sprouted to reproduce their characteristic patterns. Every DL or VL cell that grew processes on ECM developed the appropriate $Y$ or T-shaped pattern. On Con A, most but not all of the cells showed specific $Y$ or $T$ patterns. The probability of sprouting was higher on Con A than on ECM.

3. Disruption of microtubular assemblies in freshly isolated DL and VL cells by treatment with nocodazole did not affect the later outgrowth of specific patterns in culture.

4. These results provide evidence that adult $D L$ and VL leech neurons retain intrinsic information for determining a variety of their properties in culture: In particular, they reproduce type-specific neuritic patterns in the absence of extrinsic guidance cues. Moreover, the intrinsic pattern determining mechanism is not lost after the destruction of microtubular arrays within the cytoskeleton.

A striking feature of the nervous system is the wide variety of distinctive shapes and branching patterns exhibited by neurons. The development of precise morphologies by individual cells constitutes a key mechanism for the establishment of neuronal circuits. Extrinsic factors that influence the direction, form, and extent of growing processes include soluble factors such as nerve growth factor and substrate-associated molecules such as lam-

\footnotetext{
Recived Aug. 2, 1989; reviscd Scpt. 25, 1989; accepted Scpt. 27, 1989.

We wish to thank Drs. B. Stolz and H.-P. Hauri for help with the immunofluorescence, Dr. D. M. Grant for critical reading of the manuscript, as well as Ms. J. Wittker for typing the manuscript and Mr. P. Baettig for excellent photographic assistance.

This work was supported by grants from the Swiss National Fonds, 3.525-1.83 and 3.556-0.86 (to J.G.N.), and a Fellowship from Boehringer Ingelheim, FRG (to S.E.A.).

Correspondence should be addressed to Susan E. Acklin, Medical Sciences Building, University of Toronto, Toronto, Ontario M5S 1A8, Canada

Copyright (C) 1990 Society for Neuroscience $0270-6474 / 90 / 041082-09 \$ 02.00 / 0$
}

inin (Levi-Montalcini, 1975; Green and Shooter, 1980; Edgar et al., 1984; Letourneau, 1985; Chiquet et al., 1988).

A natural question concerns the extent to which intrinsic information stored within a neuron can specify its individual outgrowth pattern. Specific, identified axons in grasshopper and in zcbra fish cmbryos grow in different patterns when presented with identical molecular cues (Raper et al., 1983; Eisen et al., 1986). The morphological features of a cell can also be reproduced in culture. Thus, the daughter cells of mouse fibroblast 3T3 cells exhibit similarities in paths of migration, cell shape, and geometry of microfilament bundles (Albrecht-Buehler, 1977) and mitotic sister neuroblastoma cells display similar forms in culture (Solomon, 1979). Another striking example is provided by dispersed cultures of fetal rat hippocampal neurons; these cells develop morphological features similar to those of their counterparts in vivo (Banker and Cowan, 1977; Dotti et al., 1988).

In the present experiments we made use of 2 identified leech neurons with unusual branching patterns to analyze how inherent mechanisms can specify the shape of a cell. Many leech neurons can be identified by morphological, biochemical, and electrophysiological criteria; in culture, they retain their electrophysiological properties and the ability to form specific chemical or electrical synapses (Fuchs et al., 1981). It has also been shown that when plated onto appropriate substrates such as Concanavalin A (Con A) or leech extracellular matrix extract (ECM) isolated neurons grow rapidly and extensively; each type of neuron shows a distinctive growth pattern (Chiquet and Acklin, 1986).

The cells used in this study, known as dorsolateral (DL, 61) and ventrolateral (VL, 21), are small neurons that contain serotonin (5-HT). In the ganglion they display unusual, easily recognizable morphologies. Each cell has a single, large neurite that extends from the soma and bifurcates into 2 major branches pointing in opposite directions (Fig. 3). For DL the initial angle of bifurcation is $60^{\circ}$, which results in a Y-shaped morphology; for VL it is $180^{\circ}$, which results in a T-shaped morphology (Lent, 1981; Nusbaum and Kristan, 1986). It will be shown that when DL and VL cells are cultured in absence of extrinsic guidance factors, they reproduce outgrowth patterns similar to the morphology established during development in vivo. As a first step in determining how intrinsic information is stored within the cell, microtubular assemblies were reversibly disrupted by application of nocodazole (De Brabander et al., 1976; Hoebeke et al., 1976; Solomon, 1980). Aftcr the neurons had recovered, we analyzed the new patterns of outgrowth.

Another aim of our experiments was to assess whether the types of synaptic connections established by a neuron were in- 

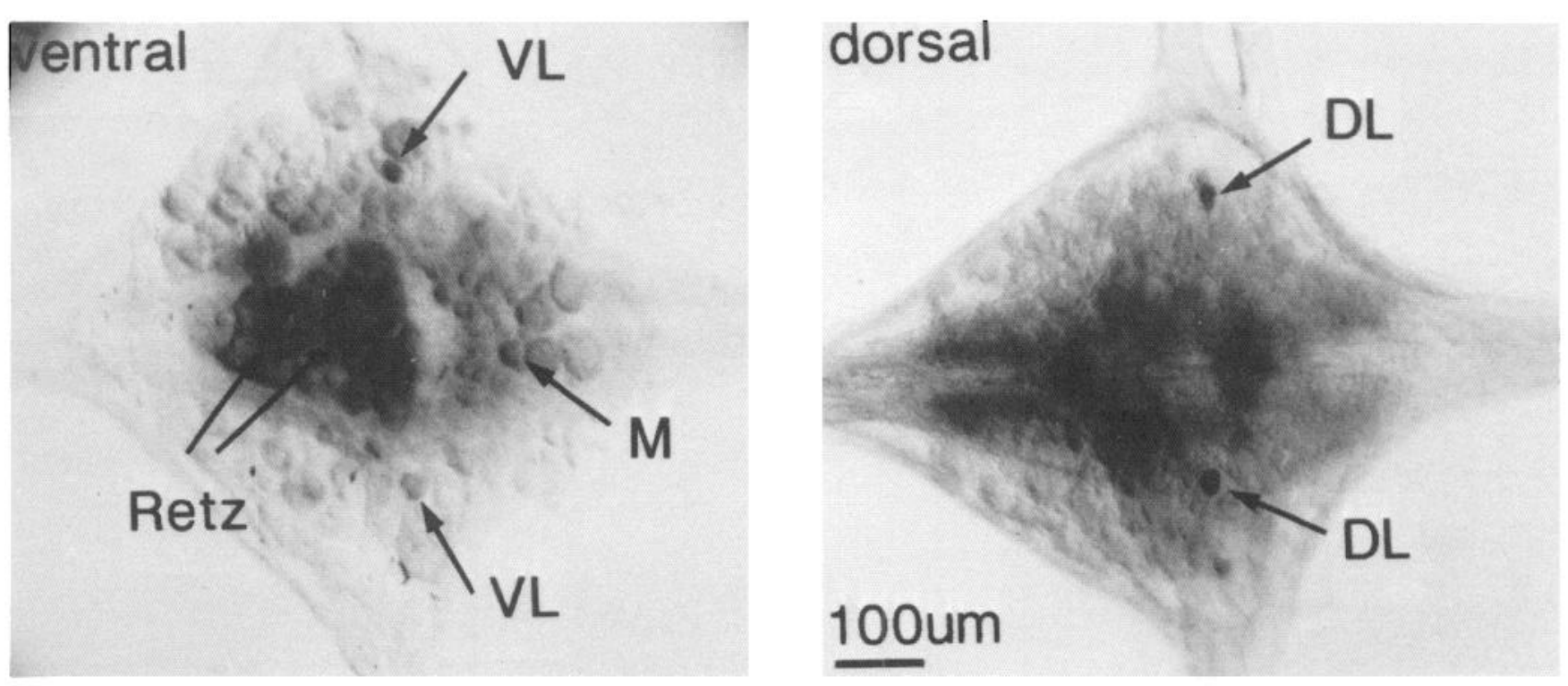

Figure 1. 5-HT-containing neurons in a leech ganglion stained with Neutral red (living, unfixed preparations). $A$, Ventral view: $V L$, Retzius, $M$, cells. $B$, Dorsal view: DL cells. In $A$ and $B$, anterior is to the left.

fluenced by its transmitter. Would all cells containing 5-HT make identical synapses on the same postsynaptic target? It will be shown that the synaptic connections made by DL and VL cells on $\mathrm{P}$ sensory cells in culture were different from those formed by Retzius cells (which also contain 5-HT). Moreover, DL and VL cells retained their membrane characteristics and the ability to produce rhythmical bursts of impulses in culture.

\section{Materials and Methods}

Experiments were made on 2 small, 5-HT-containing interneurons (DL and VL) isolated from the CNS of the leech (Hirudo medicinalis).

Identification of $D L$ and $V L$ within the ganglion and culturing method. Methods for isolating single neurons from the leech CNS have been described previously (Dietzel et al., 1986). Individual ganglia were dissected from the CNS of the leech and pinned in a Sylgard-coated dish in Leibovitz L-15 medium (GIBCO) supplemented with 2 mм glutamine (GIBCO), $6 \mathrm{mg} / \mathrm{ml}$ glucose, $0.1 \mathrm{mg}$ gentamicin sulfate (Garamycin; Schering, Kenilworth, $\mathrm{NJ}$ ) $/ \mathrm{ml}$, and $2 \%$ fetal bovine serum (Kansas City Biological, Lenexa, KS). The connective tissue capsules surrounding the ganglia were opened with forceps, and the ganglia were incubated for 1 $\mathrm{hr}$ at room temperature in collagenase/dispase (Boehringer Mannheim; $2 \mathrm{mg} / \mathrm{ml}$ in L-15 medium). To identify 5 -HT-containing cells and in particular DL and VL, Neutral red (Sigma; $1 \mathrm{mg} / \mathrm{ml}$ supplemented L-15 medium plus collagenase/dispase) was added 20 minutes before the end of the enzyme digestion (Stuart et al., 1974; Lent et al., 1979). Figure 1 shows Neutral red-stained 5-HT-containing neurons within a leech ganglion. After the enzyme and Neutral red treatment, the ganglia were washed extensively with supplemented L-15 medium. Single, stained DL and VL cells - and in certain experiments Retzius and medial (M) cells-were removed from the ganglion by suction into a fire-polished glass capillary. The cells were washed by transferring them through several drops of sterile, supplemented L-15 medium. After $10 \mathrm{hr}$, cells were plated in culture Dishes (Falcon F-3034) coated with Con A (Sigma, $2 \mathrm{mg} / \mathrm{ml}$ ) or with EDTA leech ECM extract (kindly provided by Ms. S. Grumbacher). The yield of Neutral red-stained DL and VL cells was low because of their small size and fragility. Cells could survive for up to 2 weeks in culture. Stained and nonstained Retzius cells did not show morphological or electrophysiological differences (Stuart et al., 1974; Lent and Frazer, 1977).

Dye fills. Procedures for filling cells with Lucifer yellow and HRP have been described elsewhere (Muller and McMahan, 1976; Stewart, 1978). To fill single DL and VL cells in culture with Lucifer yellow, the tips of microelectrodes (Haer Ultratip Omegadot 30-30-0, 30-40 M $\Omega$ resistances) were filled with $3 \%$ Lucifer yellow and backfilled with 0.1 M lithium chloride (Sigma). Hyperpolarizing pulses $(500 \mathrm{msec}, 1 \mathrm{~Hz}$, 1-8 $\mathrm{nA}$ ) were applied for 1-10 min. After allowing 5-10 min for diffusion the live, unfixed preparations were photographed with Kodak Tri-X film. To pressure-inject HRP into identified VL and DL neurons within the ganglion, the tips of microelectrodes (thick-wall Haer Ultratip Omegadot 30-30-1) were filled with $20 \mathrm{mg}$ HRP (Sigma, Type VI) and $2 \mathrm{mg}$ Fast green (Sigma) dissolved in $1 \mathrm{ml}$ potassium acetate $(0.2 \mathrm{M})$. Electrode tips were bevelled to a resistance of 30-40 M 2 . HRP was injected by applying pressure. After a diffusion time of $2-3 \mathrm{hr}$ the preparations were fixed and then developed.

Selection of cells for measurement of neurite outgrowth in culture. Not all healthy DL and VL cells plated on Con A or ECM grew neurites (see also Results). Healthy cells were reliably recognized by their rounded and shiny appearance. These observations were confirmed by electrophysiological measurements. For assessment of growth we selected only the cells that had sprouted. Healthy cells without neurites were not considered. On Con A about $60 \%$ of all plated, healthy cells sprouted. On ECM, however, only about $15 \%$ of all healthy cells grew out, and most of those that did, sprouted only after a delay of 6-8 d (see Results).

Assessment of outgrowth and pattern formation. The outgrowth patterns of DL and VL cells in the ganglion and in culture were photographed, and the angle between the initial major branches was measured.

A number of variables had to be taken into account for the qualitative and quantitative assessment of $\mathrm{T}$ or $\mathrm{Y}$ patterns in culture: these included degree of attachment to the substrate and different lengths of axonal stump. After removal of DL and VL cells, an axonal stump of variable length (between a few microns and several cell diameters) remained attached to the soma. All neuronal arborization had been cut off at the end of the stump. When the axonal stump was short or hidden, the cell soma was carefully moved with a glass pipette to observe the sites from which growth arose. We did not measure minor processes growing out directly from the cell soma.

Nocodazole treatment. A stock solution of nocodazole (Sigma, $3 \mathrm{mg}$ / ml DMSO) was prepared. Freshly isolated Retzius, DL, and VL cells were incubated with nocodazole at a final concentration of $10 \mu \mathrm{g} / \mathrm{ml}$ supplemented L-15 medium for $20 \mathrm{~min}$. The controls were incubated with the corresponding amount of DMSO alone. Cells were washed extensively in supplemented L-15 medium. 

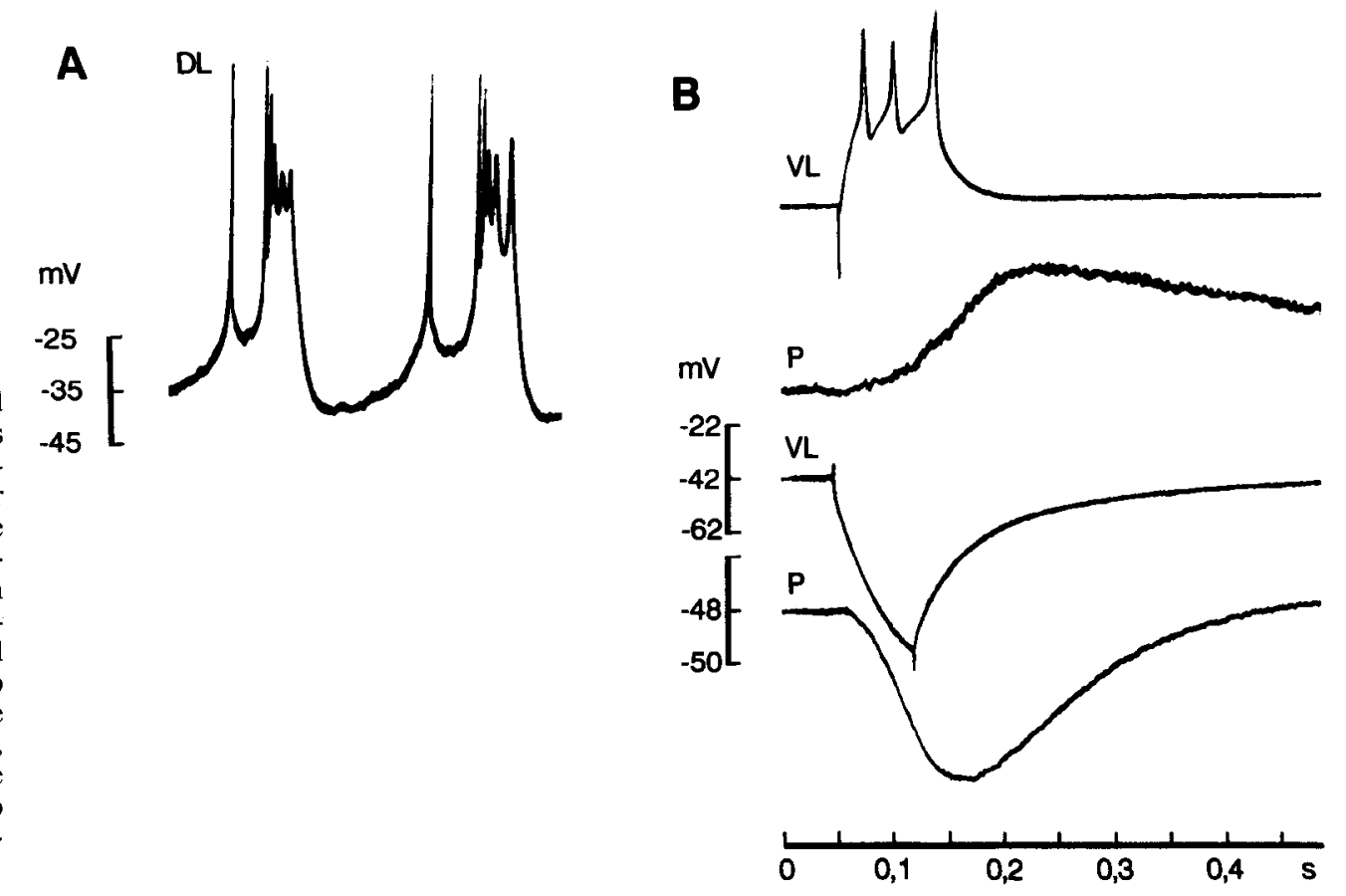

Figure 2. Membrane properties and synaptic connections of DL and VL cells in culture. $A$, Spontaneous bursting pattern displayed by DL cell in culture for $3 \mathrm{~d}$. Two bursts of a long series are shown. Continuous rhythmical discharges were observed for up to $15 \mathrm{~min}$ in DL and VL cells. $B$, Electrical synapse formed between a VL and a $\mathrm{P}$ cell in culture for $3 \mathrm{~d}$. Current injected into the VL cell (upper traces) spread to the $P$ cell in both directions. Retzius cells, which like VL cells contain 5-HT, make purely chemical synapses on $P$ cells. No chemical component was observed between VL or DL cells and P cells.
In some experiments, freshly isolated, nocodazole-treated cells were left in supplemented L-15 medium for a $10 \mathrm{hr}$ recovery period before plating them on Con A.

Immunofluorescence. Antibody staining of microtubules in isolated Retzius cells in culture was performed according to procedures described elsewhere (Eilers et al., 1989). Retzius cells cultured on Con A-coated petri dishes (Falcon 3080) were fixed for $30 \mathrm{~min}$ with 3\% $p$-formaldehyde-PBS at room temperature, washed with PBS, quenched with 20 $\mathrm{mM}$ glycine in PBS, and permeabilized with $0.1 \%$ (wt/vol) saponin in PBS containing $20 \mathrm{~mm}$ glycine for $20 \mathrm{~min}$. Cells were stained either with rat monoclonal antibodies against $\alpha$-tubulin (clone YL1/2, 1:5 diluted, generously provided by Dr. J. Wehland, Goettingen) or with polyclonal rabbit antiserum raised against sea urchin tubulin (Cappel Laboratories, Malverne, PA, 1:200 diluted) for $20 \mathrm{~min}$ at room temperature. The secondary antibodies used were rhodamine-conjugated goat anti-rat IgG and a fluorescine-conjugated goat anti-rabbit IgG (Cappel Laboratories, Malverne, PA, 1:200 diluted).

\section{Results}

\section{Electrical properties of $D L$ and VL cells and synapse formation in culture}

In culture, DL and VL cells continued to display resting and action potentials similar to those observed in situ. DL and VL cells show bursts of rhythmical activity in the ganglion (Nusbaum and Kristan, 1986). A characteristic feature of the isolated DL and VL neurons was that they continued to fire bursts of action potentials in the absence of synaptic inputs. The spontaneous bursting was abolished by $1 \mathrm{~mm} \mathrm{CdCl}_{2}$. Discharges of isolated DL cells in culture for $3 \mathrm{~d}$ are shown in Figure $2 A$.

Experiments were made to test whether DL and VL neurons formed specific synapses in culture. DL, VL, Retzius (Retz), and $M$ cells (all of which contain 5-HT) were paired in different combinations. We found that DL-DL, VL-VL, M-M, and RetzRetz, as well as DL-VL, DL-Retz, and VL-Retz, all became electrically coupled by nonrectifying junctions in culture, as in the ganglion (Lent and Frazer, 1977).

In culture, Retzius cells have been shown to form chemical synapses upon pressure sensory cells (P) using 5-HT as a trans- mitter; no electrical coupling develops between Retzius and $\mathrm{P}$ cells (Fuchs et al., 1982). Although DL and VL cells contain 5-HT (Rude et al., 1969; Lent et al., 1979), they formed purely electrical synapses on $\mathrm{P}$ cells with no chemical component (Fig. $2 B$ ). These results show that the specificity of synapse formation by a neuron is not determined by its transmitter: Three types of neurons, all 3 of which contain 5-HT, make different patterns of synaptic connections with the same target.

Quantitative comparisons of branching patterns made by $D L$ and VL cells in culture and in ganglia

Figure 3 shows a DL (Y-shaped) cell and a VL (T-shaped) cell that had been stained with Neutral red and then injected with HRP in the ganglion. The initial angle between the 2 major branches of DL cells was $66^{\circ} \pm 3.4^{\circ}(\mathrm{SD}, n=5)$; for VL, it was $180^{\circ} \pm 2.1^{\circ}(n=5)$. Other cells in leech ganglia with their more complex geometries cannot be simply characterized in this way. Examples of the $\mathrm{Y}$ and $\mathrm{T}$ patterns formed by $\mathrm{DL}$ and VL in culture are shown in Figures 4 and 5.

One difference in culture was variability in the length of outgrowth preceding the bifurcation. Although some DL and VL cells grew neurites that extended beyond the stump before branching, others bifurcated at once. In such cells, the angle of bifurcation could still be measured if the soma was displaced by a microelectrode (see Materials and Methods). The angles of bifurcation were strikingly similar in culture and in the ganglion. For DL cells in culture, the angle was $70^{\circ} \pm 16.3^{\circ}(n=23)$, compared with $66^{\circ}$ in the ganglion. For VL cells, the values were $170^{\circ} \pm 16.5^{\circ}(n=23)$ compared to $180^{\circ}$ in the ganglion. Bipolar, $\mathrm{Y}$ or $\mathrm{T}$ patterns were never displayed by other leech neurons growing in culture. For comparison, Figure 6 shows Retzius cclls growing on ECM and Con A substrates. As in earlier experiments (Chiquet and Acklin, 1986), Retzius cells branched on both substrates with distinctive patterns, neither of which resembled a simple $\mathrm{Y}$ or $\mathrm{T}$. 

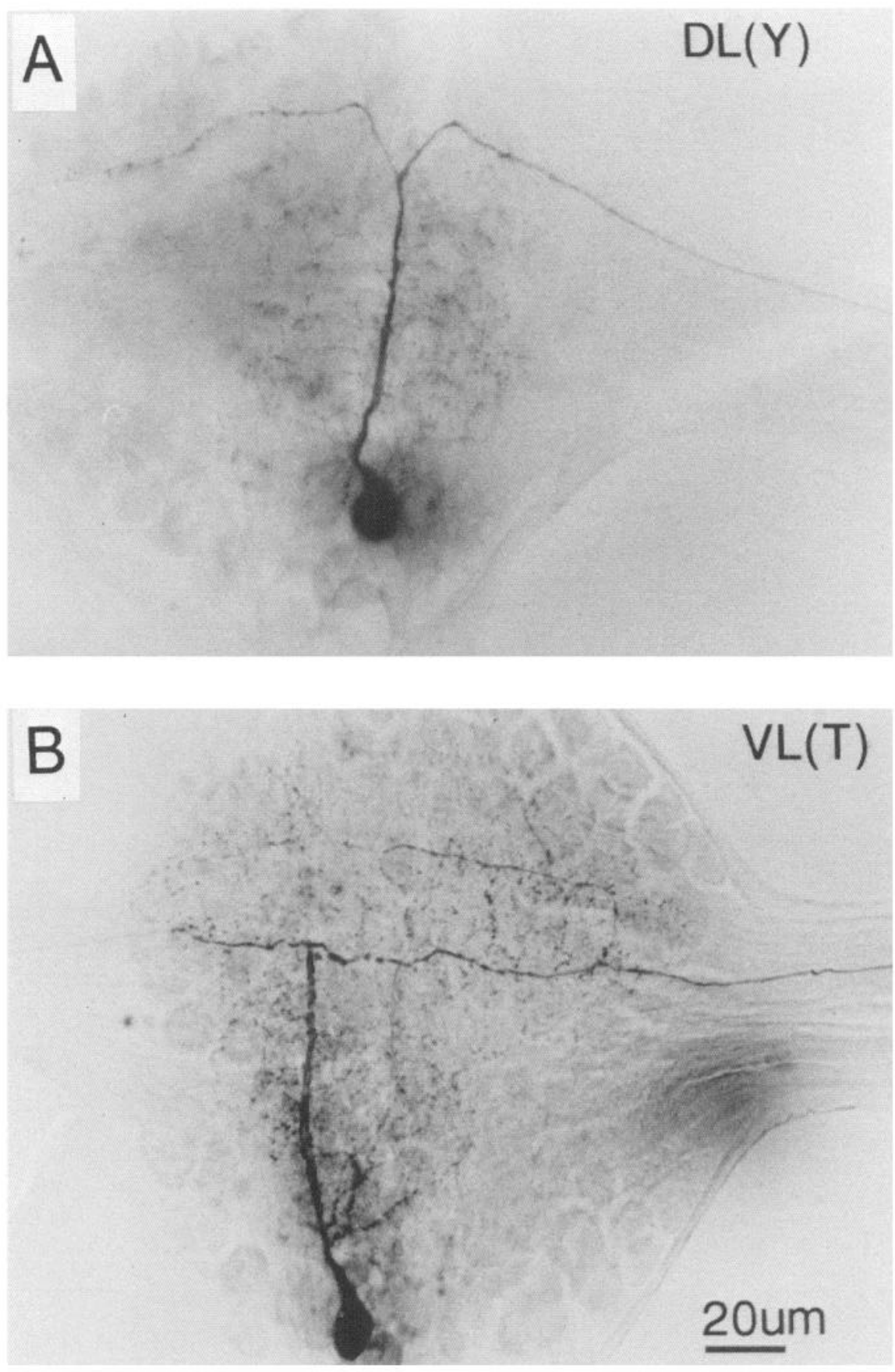

Figure 3. Characteristic branching patterns of $(A)$ DL and $(B)$ VL cells in a leech ganglion. These cells were identified by staining with Neutral red and then pressure-injected with HRP.

\section{Influence of substrates on branching patterns}

Branching patterns of DL and VL cells were more variable on Con A than on ECM. On Con A, $30 \%$ of the DL and VL cells grew out in ill-defined configurations; the remaining $70 \%$ formed the appropriate $\mathrm{Y}$ or $\mathrm{T}$ patterns. By contrast, although fewer cells sprouted on ECM (see below), $100 \%$ of those DL and VL cells that did sprout reproduced the appropriate $\mathrm{T}$ or $\mathrm{Y}$ patterns. A further characteristic difference was that DL and VL cells produced more branches on Con A than on ECM; in addition, the individual neurites were more curved on Con A (Figs. 4, 5). Comparable effects of substrate on the number and curvature of branches have been observed with other types of leech neurons (Chiquet and Acklin, 1986; Grumbacher-Reinert, 1989).

Con A and ECM also influenced the time course and success rate of neurite outgrowth by DL and VL cells. On Con A, approximately $60 \%(n=50)$ of all healthy, plated DL or VL cells showed neuronal outgrowth, whereas on ECM only $15 \%(n=$ 50 ) of all plated cells grew out (see also Materials and Methods). When neuronal outgrowth of DL and VL cells on ECM did occur it began late after a delay of 6 to $8 \mathrm{~d}$ (Fig. 7). These findings for DL and VL cells differ from other leech neurons, which sprout well on both substrates but more rapidly on ECM than on Con A (Chiquet and Acklin, 1986; Grumbacher-Reinert, 1989). 
A
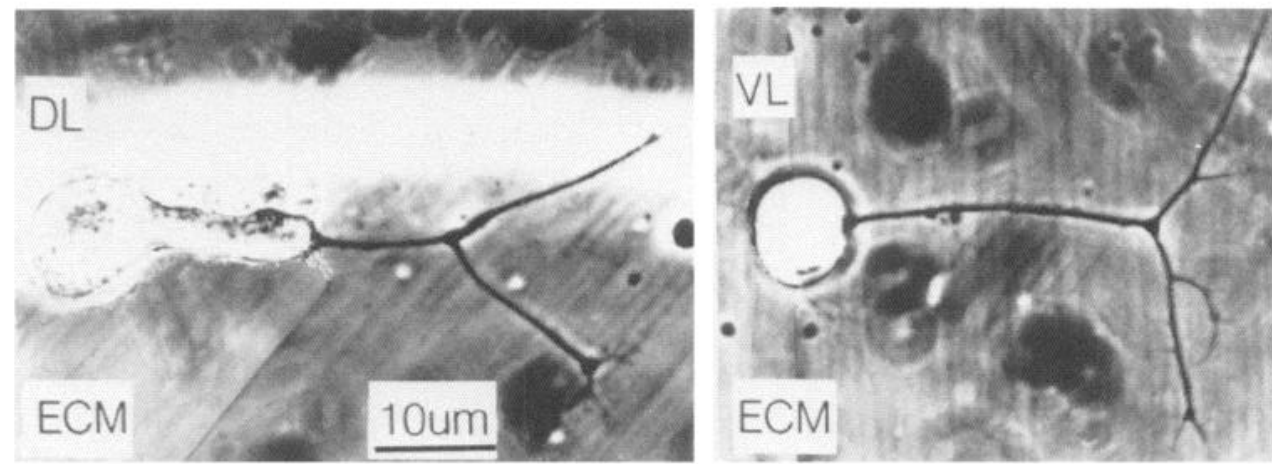

Figure 4. Outgrowth patterns of DL and VL cells cultured for $10 \mathrm{~d}$ on ECM. Sprouting originated from the axonal stump. Sprouts (arrows) in $B$ belong to a cocultured Retzius cell. Note the variability in lengths of outgrowth from the stump before the bifurcation into $\mathrm{T}$ or $\mathrm{Y}$ branches $(C, D)$.
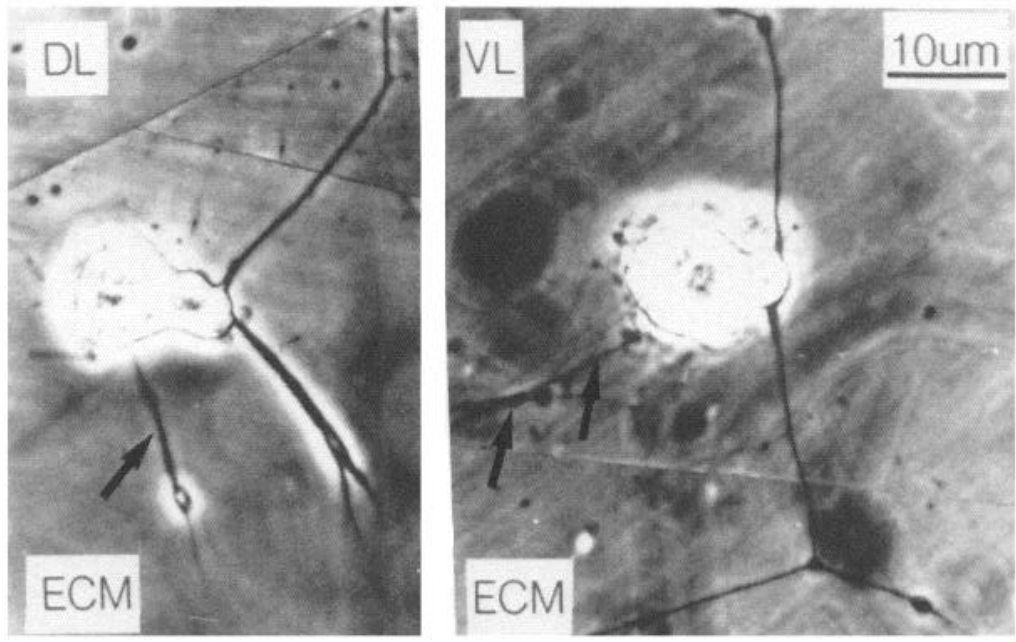

A
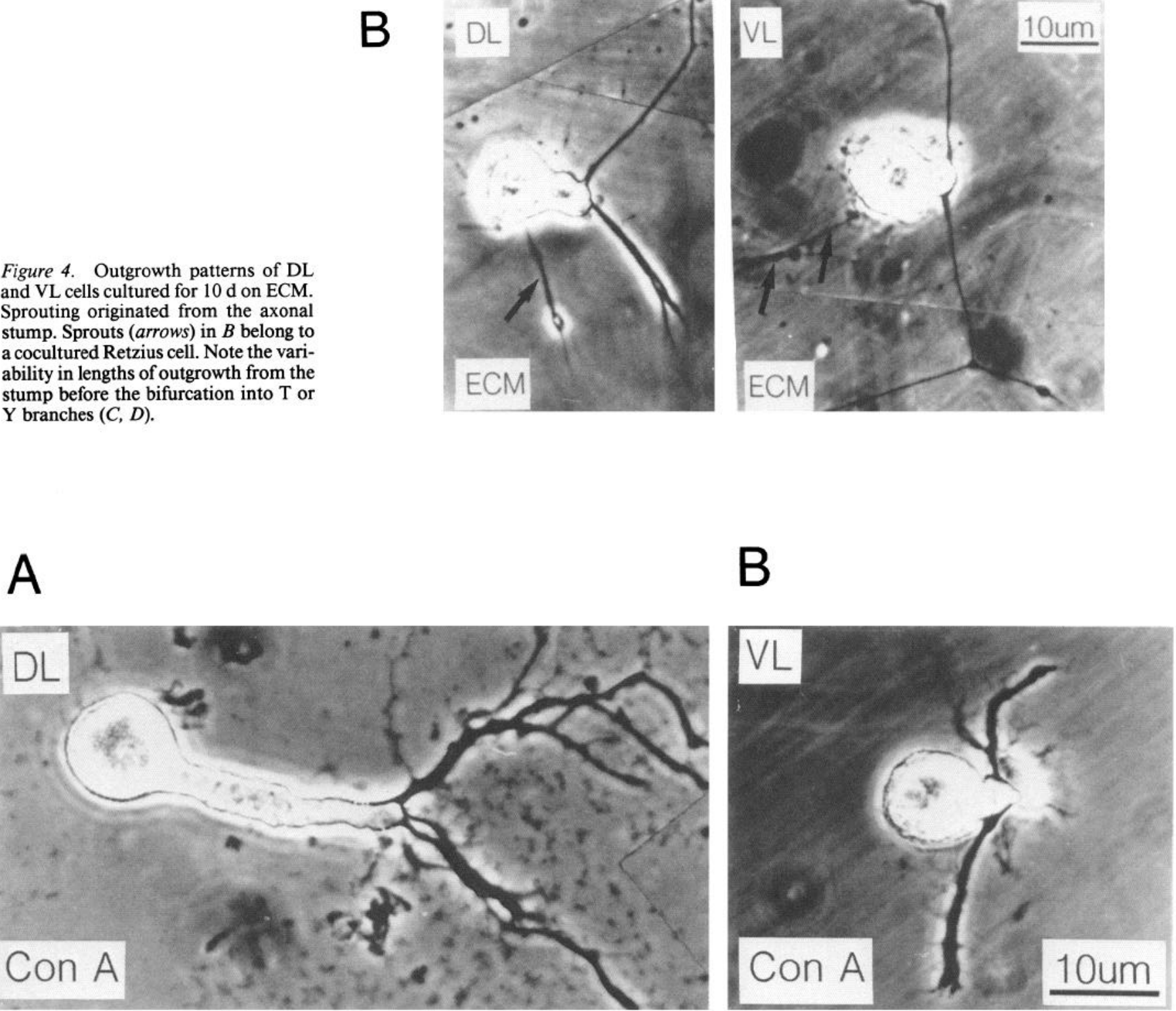

Figure 5. Sprouting patterns of DL $(A)$ and VL $(B)$ cells cultured for $3 \mathrm{~d}$ on Con A. The Y and T patterns are apparent. Note the thicker, more branched processes on Con A compared with ECM. 
A

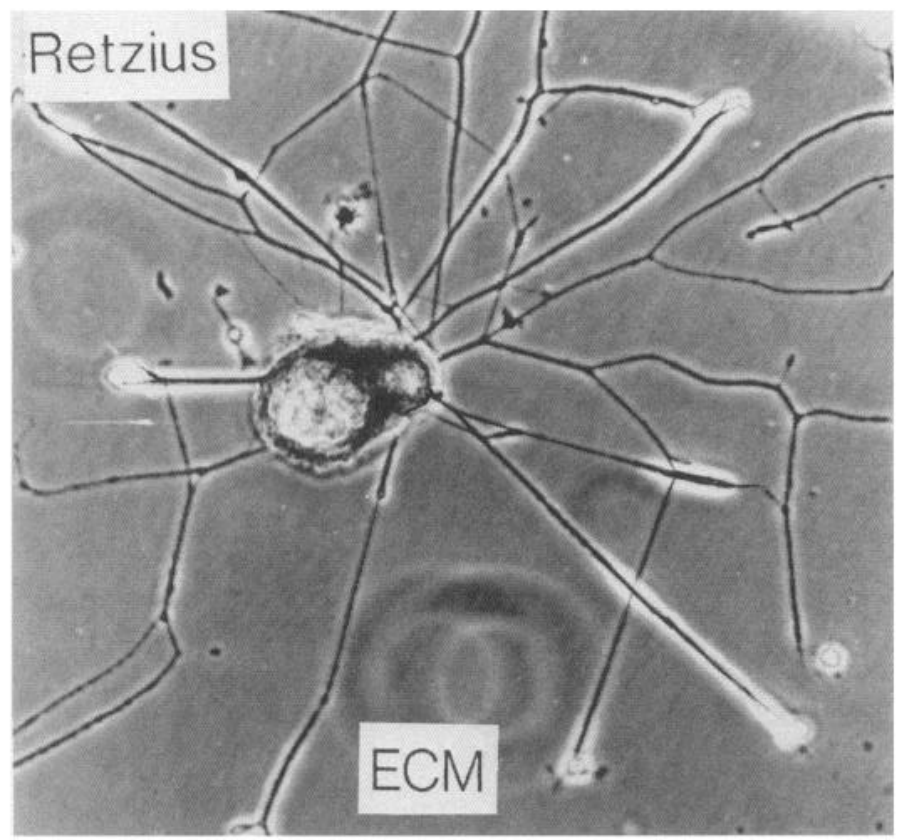

B

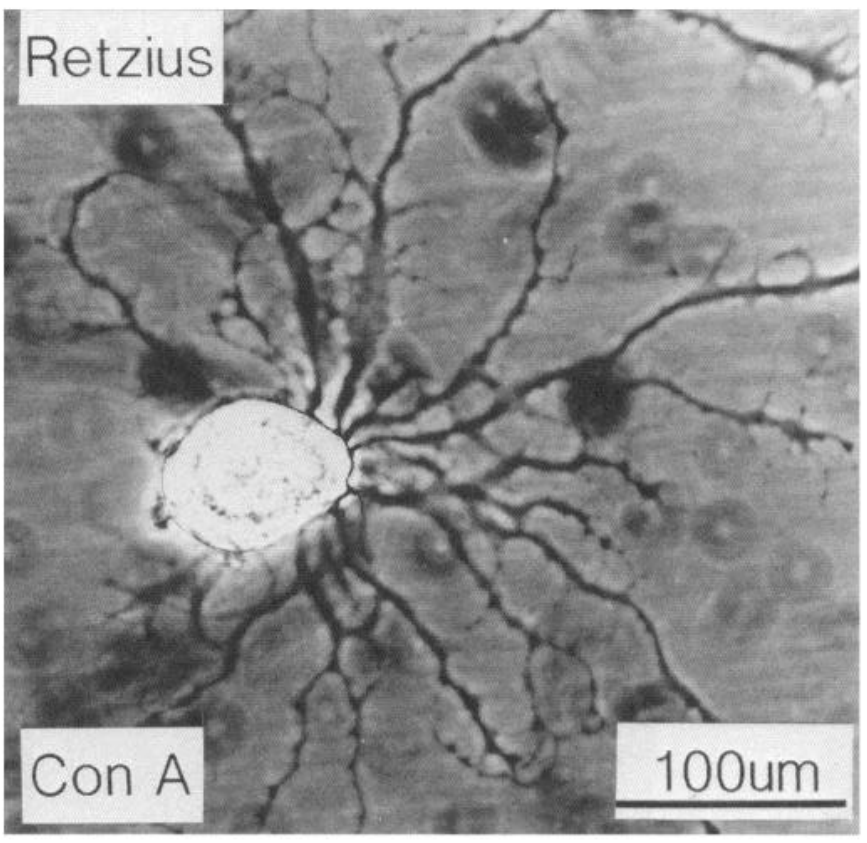

Figure 6. Outgrowth patterns of Retzius cells, cultured for $3 \mathrm{~d}$ on $\mathrm{ECM}(A)$ and Con $\mathrm{A}(B)$. The branching conforms to no simple $\mathrm{T}$ or $\mathrm{Y}$ configuration. The differences on Con A and ECM resemble those described earlier, with straighter, finer, less curved, less branched processes on ECM. Note the rapid growth on ECM.

\section{Outgrowth of DL and VL in culture after disruption of microtubular arrays by nocodazole}

The aim of the following experiments was to test whether DL and VL cells reproduced their original patterns in culture because of specific preexisting microtubular arrays within the cytoskeleton. A drug that disrupts microtubules (nocodazole) was applied to test whether Y- and T-shapes could still be reproduced (De Brabander et al., 1976; Hoebeke et al., 1976; Solomon, 1980; Eilers et al., 1989). Immunofluorescence micrographs of the cytoskeleton were made in freshly isolated leech neurons labeled with anti-tubulin antibody. These pictures were compared with those obtained after treatment with nocodazole. Retzius cells rather than DL or VL were used because of their larger size and ease of dissection without Neutral red (see Discussion). Incubation in $10 \mu \mathrm{g} / \mathrm{ml}$ nocodazole for $20 \mathrm{~min}$ destroyed all of the cytoskeletal microtubular arrays in Retzius cells (Fig. 8; see also Discussion). Moreover, nocodazole-treated Retzius cells grew out in broad veil-like structures (Fig. 9C). Isolated DL and VL cells were similarly treated with nocodazole, after which they were allowed to recover for $10 \mathrm{hr}$ and plated on Con A. Figure $9 \mathrm{~A}$ shows the sprouting pattern of a nocodazole-treated DL cell after $1 \mathrm{~d}$ in culture. The outgrowth was highly symmetrical. The 2 broad, flat growth cones appeared similar in their divergence to the bipolar outgrowth of normal DL cells. The outgrowth of VL cells after nocodazole treatment also appeared bipolar, resembling the pattern of untreated VL cells (Fig. 9B). In contrast, other neurons, such as Retzius cells (Fig. 9C), treated and cultured under the same conditions showed no bipolar outgrowth patterns. Although the outgrowth patterns after nocodazole treatment showed recognizable differences for DL and VL cells, quantitative measurements of initial out- growth angles were not possible because of the diffuse, ill-defined structures of the processes.

\section{Discussion}

Adult leech neurons in culture retain their membrane properties and the ability to form specific synapses. Thus, Retzius cells continue to give characteristic impulses and can form chemical

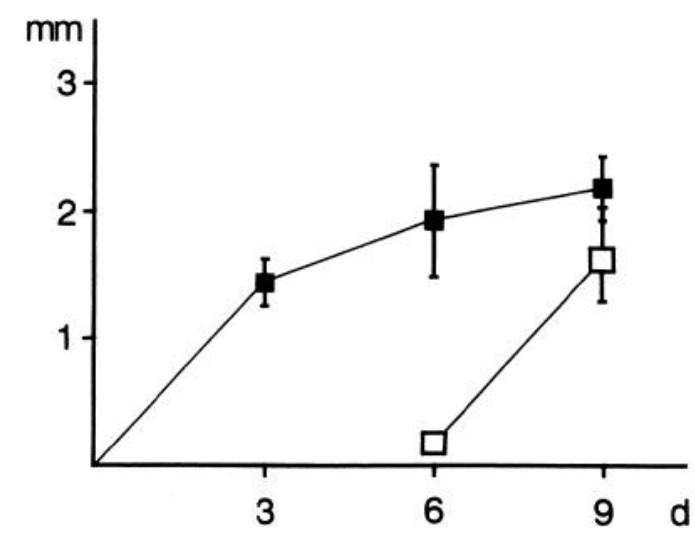

Figure 7. Time course of neurite outgrowth of DL and VL neurons

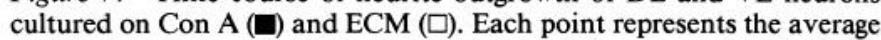
neurite length per cell, measured from at least 5 neurons. Bars indicate SEMs. Note that growth did not begin on ECM for $6 \mathrm{~d}$ or more. By contrast, other cells (such as Retzius or AP cells) grew from the outset on both ECM and Con A, with growth rates that were significantly faster on ECM. Once DL and VL did grow on ECM, they grew rapidly (see Materials and Methods for description of how cells were selected for measurement). 

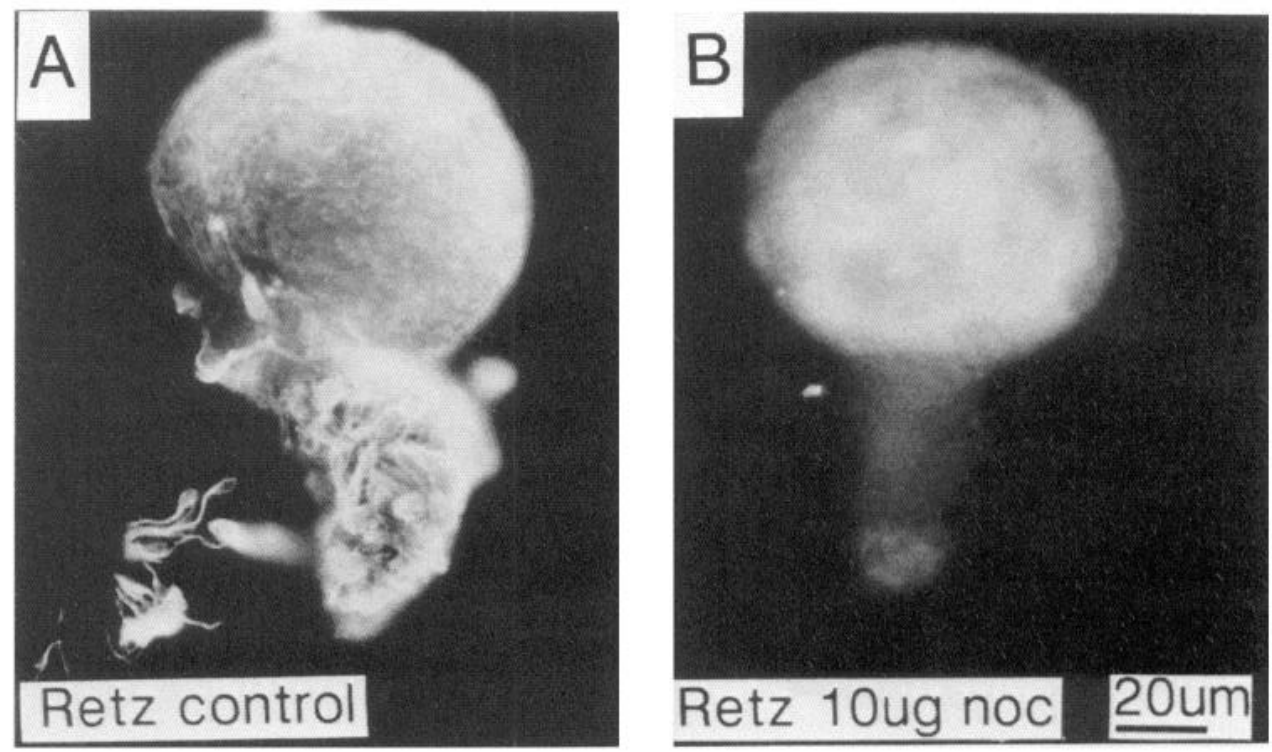

Figure 8. Effect of nocodazole on cytoskeleton. $A$, Untreated control Retzius cell, labeled with a polyclonal rabbit antiserum raised against sea urchin tubulin; $B$, Retzius cell, labeled with the same anti-tubulin antibody as the control cell, after treatment with $10 \mu \mathrm{g} / \mathrm{ml}$ nocodazole. $C$, Axonal stump of the same cell as shown in $A$. $D$, Axonal stump of the same cell as shown in $B$. Both control and treated cells were focused in the same plane by Nomarski optics prior to fluorescence photography. Note the absence of labeled structures in the nocodazole-treated Retzius cell. Retzius cells rather than DL or VL were chosen because of their large size and the reliable identification without Neutral red.
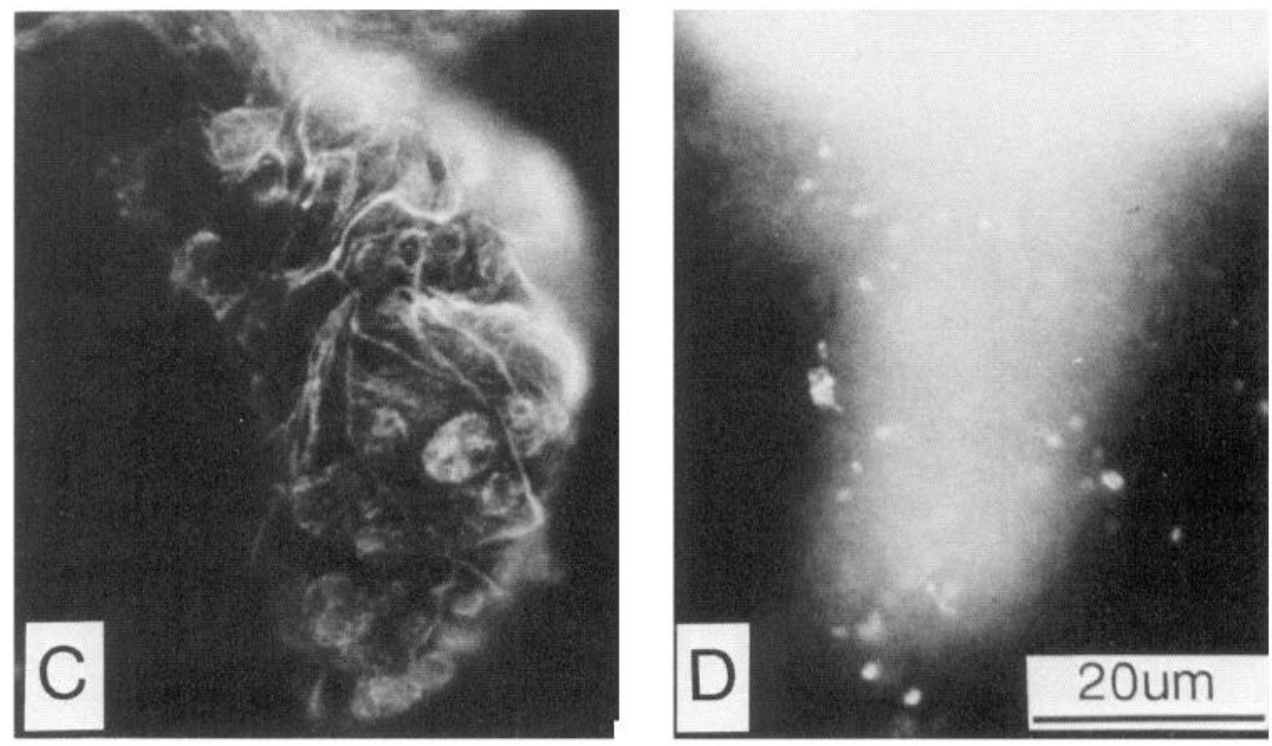

synapses with one cell, the P cell, and electrical synapses with other cells (Fuchs et al., 1982). In culture, as in the ganglion, DL and VL cells became electrically coupled with other serotonergic neurons such as DL, VL, Retzius, and the M cell. Unlike Retzius cells, DL and VL formed electrical connections and did not form chemical synapses with the P cell (Fuchs et al., 1981, 1982). This result shows that 2 cells with the same transmitter can form different connections in culture with specific targets. DL and VL cells were unusual in their ability to produce spontaneous bursts of action potentials in culture.

An even more unusual property of DL and VL cells was the reproduction of the original arborization patterns in the absence of external cues. Thus, Retzius and other leech cells grow in highly distinctive patterns on Con A and ECM substrates, but the final picture is quite different from that produced in the ganglion by normal development (Grumbacher-Reinert, 1989). By contrast, adult DL and VL leech neurons appear to be provided with intrinsic information that specifies their pattern of outgrowth, in the absence of extrinsic guidance factors.
A technical difficulty in our experiments was to measure quantitatively the extent to which original patterns were reproduced. One clear result was that outgrowth was bipolar. Moreover, the angles between the first major branches were accurately reproduced. Even in those cases where the neuronal outgrowth originated directly at the axonal stump and was not preceded by a single neurite, the initial branches grew out at about the same angles as they did in the ganglion. To assess whether a $\mathrm{T}$ or $\mathrm{Y}$ had been formed when the axonal stump was hidden, we carefully displaced the cell soma with a glass pipette. In a few cells on Con A, neurites also grew out directly from the cell soma. We ignored those processes and measured only outgrowth originating at the axonal stump, since (1) the branches, originating from the cell soma, were thin and scattered, and (2) we never saw sprouting from the cell soma on ECM, which is an endogenous substrate (Chiquet and Acklin, 1986; Chiquet et al., 1988).

The resemblance between branching patterns in the ganglion and in culture was only certain for the initial outgrowth of major branches. For DL cells in the ganglion, the initial branching 

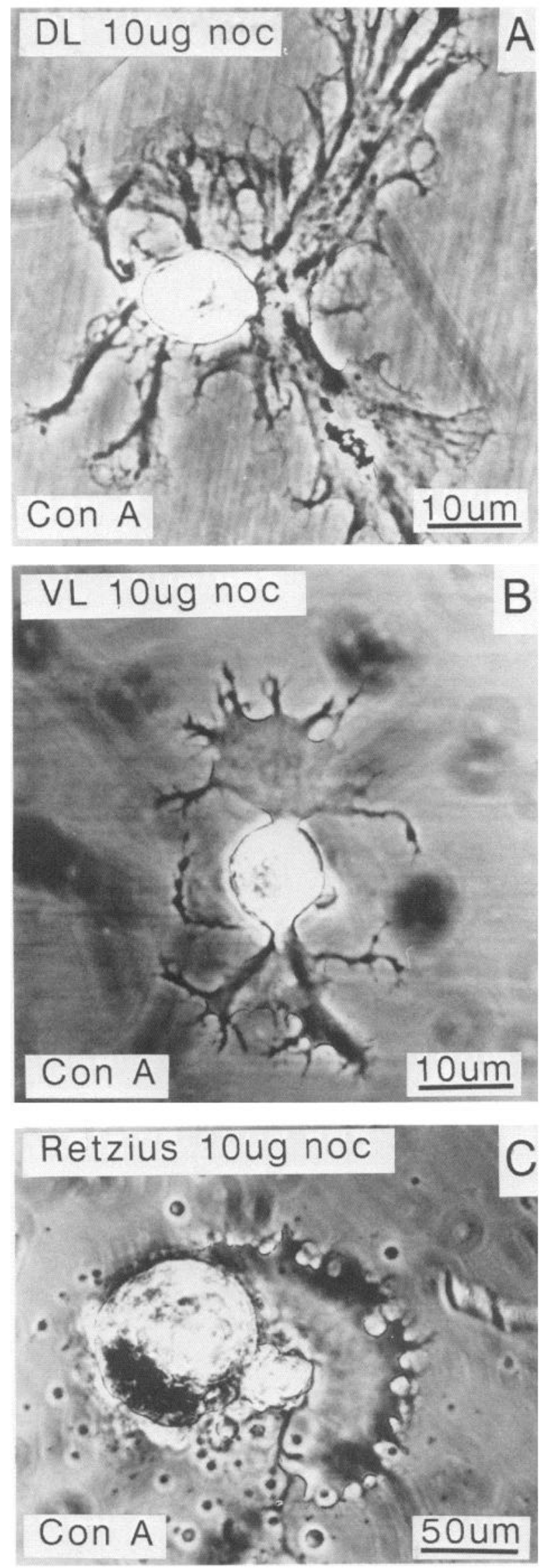

angle of $60^{\circ}$ later widens to $180^{\circ}$. In culture only the initial angle of $60^{\circ}$ was reproduced. The initial single neurite, which in the ganglion precedes branching, was reproduced by only a few cells in culture: often only a short piece of axonal stump preceded the first branching point. A possible explanation could be that outgrowth of the single initial neurite in the ganglion is triggered during development and later guided by extrinsic factors (e.g., substrate-bound or soluble molecules).

Both substrates on which the DL and VL cells were plated permitted the reproduction of a T-shaped (VL) or Y-shaped (DL) pattern. There were differences, however. On ECM, virtually all cells that grew formed the type specific $\mathrm{T}$ or $\mathrm{Y}$ patterns. On Con A about $30 \%$ of the cells grew out randomly, and the branching frequency of the neurites was higher.

A distinctive property of both DL and VL cells was that relatively few cells showed any neuronal outgrowth at all on ECM. Those that did, grew after a delay of $6-8 \mathrm{~d}$. This is in marked contrast to the rapid sprouting on ECM observed with other types of leech neurons, such as Retzius or anterior pagoda cells. These results confirm that molecules anchored in the ECM can exert qualitatively different, contact-mediated influences on different types of neurons (Chiquet and Nicholls, 1987; Chiquet et al., 1988).

\section{Outgrowth of DL and VL in culture after disruption of} microtubular arrays by nocodazole

Previous studies have suggested that specifically arranged microtubular arrays, microtubule-organizing centers (MTOCs), and microtubular-associated proteins (MAPs) might be involved in the establishment and maintenance of neuronal morphology (Yamada et al., 1970; Solomon, 1980; Bartlett Bunge, 1986; Matus, 1987, 1988).

In the present studies, the depolymerizing drug nocodazole was used to destroy microtubular arrays reversibly. Nocodazole disrupts microtubular structures in a variety of systems and is in many respects preferable to colchicine (De Brabander et al., 1976; Hoebeke et al., 1976; Solomon, 1980; Eilers et al., 1989). For technical reasons the effect of nocodazole on leech neurons was first tested on Retzius cells cultured on Con A. Retzius cells have a considerably larger cell diameter $(80 \mu \mathrm{m})$ than DL and VL cells $(10 \mu \mathrm{m})$. Within the ganglion they can be identified by eye without Neutral red; they can be easily isolated and sprout readily in culture. An advantage of the large cell soma is that immunofluorescence-labeled structures can be readily seen. The following lines of evidence suggest that the labeled structures that disappeared after nocodazole treatment were microtubular arrays. (1) Antibody labeling with monoclonal and polyclonal antibodies, raised against yeast and sea urchin tubulin, labeled similar structures in control cells. In nocodazole-treated $(10 \mu \mathrm{g} /$ $\mathrm{ml}$ ) cells, only diffuse staining was observed, with no sign of distinct structures. (2) The effects of nocodazole on the labeled structures were dose dependent: We tested nocodazole concentrations of $0.1,1$, and $10 \mu \mathrm{g} / \mathrm{ml}$. Treatment with less than 10 $\mu \mathrm{g} / \mathrm{ml}$ nocodazole did not abolish all labeled structures. Treat-

Figure 9. Outgrowth patterns of DL $(A)$ and VL $(B)$ cells, treated with $10 \mu \mathrm{g}$ nocodazole and then cultured for $2 \mathrm{~d}$ on Con A. Although patterns appear different from those of untreated cells, the growth was bipolar, with a tendency to $\mathrm{Y}$ and $\mathrm{T}$ formation. $C$, Growth of Retzius cell after nocodazole treatment. Note the broad, flat, formless growth cone compared with outgrowth seen in Figure 6. 
ment of control cells with the same amount of DMSO had no effect. (3) Nocodazole-treated Retzius cells (like DL and VL cells) grew out in broad, flat, veil-like structures. Distinct fine processes were absent. Nevertheless, after disruption of microtubular assemblies, DL and VL cells, unlike Retzius cells, still grew out in a bipolar manner. This could be the result of some microtubular structures remaining after nocodazole treatment. Another explanation might be that bipolar outgrowth is organized by cytoskeletal components that are not affected by nocodazole, for example, MTOCs (Ng and Frankel, 1977; Schliwa et al., 1979; Spiegelman et al., 1979a, b). MTOCs could determine cellular morphologies by organizing selective growth of certain neurites, while others remain stationary (Kirschner and Mitchison, 1986). It will be of interest to investigate further the role of cytoskeletal components in determining the morphologies of DL and VL cells in culture and to analyze where in these cells intrinsic information for pattern formation is stored.

\section{References}

Albrecht-Buehler, G. (1977) Daughter 3 T3 cells. Are they mirror images of each other? J. Cell Biol. 72: 595-603.

Banker, G. A., and W. M. Cowan (1977) Rat hippocampal neurons in dispersed cell culture. Brain Res. 126: 397-425.

Bartlett Bunge, M. (1986) The axonal cytoskeleton: Its role in generating and maintaining cell form. TINS 9: 477-482.

Chiquet, M., and S. E. Acklin (1986) Attachment to Con A or extracellular matrix initiates rapid sprouting by cultured leech neurons. Proc. Natl. Acad. Sci. USA 83: 6188-6192.

Chiquet, M., and J. G. Nicholls (1987) Neurite outgrowth and synapse formation by identified leech neurones in culture. J. Exp. Biol. 132: 191-206.

Chiquet, M., L. Masuda-Nakagawa, and K. Beck (1988) Attachment to a laminin-like leech protein, but not to vertebrate laminin, initiates rapid sprouting by leech neurons. J. Cell Biol. 107: 1189-1198.

De Brabander, M. J., R. M. L. Van De Veire, F. E. M. Aerts, and P. A. J. Janssen (1976) The effects of methyl[5-(2-thienylcarbonyl)1H-benzimidazol-2-yl]carbamate, (R 17934; NSC 238159), a new synthetic antitumoral drug interfering with microtubules, on mammalian cells cultured in vitro. Cancer Res. 36: 905-916.

Dietzel, I. D., P. Drapeau, and J. G. Nicholls (1986) Voltage dependence of 5-hydroxytryptamine release at a synapse between identified leech neurons in culture. J. Physiol. (Lond.) 372: 191-205.

Dotti, C. G., C. A. Sullivan, and G. A. Banker (1988) The establishment of polarity by hippocampal neurons in culture. J. Neurosci. 8: 1454-1468.

Edgar, D., R. Timpl, and H. Thoenen (1984) The heparin-binding domain of laminin is responsible for its effects on neurite outgrowth and ncuronal survival. Embo J. 3: 1463-1468.

Eilers, U., J. Klumperman, and H.-P. Hauri (1989) Nocodazole, a microtubule-active drug, interferes with apical protein delivery in cultured intestinal epithelial cells (Caco-2). J. Cell Biol. 108: 13-22.

Eisen, J. S., Z. M. Myers, and M. Westerfield (1986) Pathway selection by growth cones of identified motoneurones in live zebra fish embryos. Nature 320: 269-271.

Fuchs, P. A., J. G. Nicholls, and D. Ready (1981) Membrane properties and selective connexions of identified leech neurones in culture. J. Physiol. (Lond.) 316: 203-223.

Fuchs, P. A., L. P. Henderson, and J. G. Nicholls (1982) Chemical transmission between individual Retzius and sensory neurones of the leech in culture. J. Physiol. (Lond.) 323: 195-210.

Green, L. A., and E. M. Shooter (1980) The nerve growth factor. Annu. Rev. Neurosci. 4: 353-402.
Grumbacher-Reinert, S. (1989) Local influence of substrate molecules in determining distinctive growth patterns of identified neurons in culture. Proc. Natl. Acad. Sci. USA 86: 7270-7274.

Hoebeke, J., G. Van Nijen, and M. De Brabander (1976) Interaction of oncodazole ( $R$ 17934), a new antitumoral drug, with rat brain tubulin. Biochem. Biophys. Res. Commun. 69: 319-324.

Kirschner, M., and T. Mitchison (1986) Beyond self assembly: From microtubules to morphogenesis. Cell 45: 329-342.

Lent, C. M. (1981) Morphology of neurons containing monoamines within leech segmental ganglia. J. Exp. Zool. 216: 311-316.

Lent, C. M., and B. M. Frazer (1977) Connectivity of the monoaminecontaining neurones in central nervous system of leech. Nature 28 844-847.

Lent, C. M., J. Ono, K. T. Keyser, and H. J. Karten (1979) Identification of vital-stained neurons from leech ganglia. J. Neurochem. 32: $1559-1563$.

Letourneau, P. C. (1985) Axonal growth and guidance. In Molecular Bases of Neural Development, M. Edelman, ed., pp. 269-293, Wiley, New York.

Levi-Montalcini, R. (1975) NGF: an uncharted route. In The Neurosciences: Paths of Discovery, F. G. Worden, J. P. Swaze, and G. Adelman, eds., pp. 245-265, MIT Press, Cambridge, MA.

Matus, A. (1987) Putting together the neural cytoskeleton. TINS 10 186-189.

Matus, A. (1988) Microtubule-associated proteins. Their potential role in determining neuronal morphology. Annu. Rev. Neurosci. 11:2944.

Muller, K. J., and U. J. McMahan (1976) The shapes of sensory and motor neurones and the distribution of their synapses in ganglia of the leech. Proc. R. Soc. London [Biol.] 194: 481-499.

$\mathrm{Ng}, \mathrm{F}$., and J. Frankel (1977) $180^{\circ}$ rotation of ciliary rows and its morphogenetic implications. Proc. Natl. Acad. Sci. USA 74: 11151119.

Nusbaum, M. P., and W. B. Kristan (1986) Swim initiation in the leech by serotonin containing interneurones, cells 21 and 61 . J. Exp. Biol. 122: 277-302.

Raper, J. A., M. Bastiani, and C. S. Goodman (1983) Pathfinders by neuronal growth cones in grasshopper embryos. I. Divergent choices made by the growth cones of sibling neurons. J. Neurosci. 3: 20-30.

Rude, S., R. E. Coggeshall, and L. S. Van Orden (1969) Chemical and ultrastructural identification of 5-hydroxytryptamine in an identified neuron. J. Cell Biol. 41: 832-854.

Schliwa, M., U. Euteneuer, W. Herzog, and K. Weber (1979) Evidence for rapid structural and functional changes of the melanophore microtubule-organizing center upon pigment movements. J. Cell Biol. 83: 623-632.

Solomon, F. (1979) Detailed neurite morphologies of sister neuroblastoma cells are related. Cell 16: 165-169.

Solomon, F. (1980) Neuroblastoma cells recapitulate their detailed neurite morphologies after reversible microtubule disassembly. Cell 21: 333-338.

Spiegelman, B. M., M. A. Lopata, and M. W. Kirschner (1979a) Multiple sites for the initiation of microtubule assembly in mammalian cells. Cell 16: 239-252.

Spiegelman, B. M., M. A. Lopata, and M. W. Kirschner (1979b) Aggregation of microtubule initiation centers preceding neurite outgrowth in mouse neuroblastoma cells. Cell 16: 253-263.

Stewart, W. W. (1978) Intracellular marking of neurons with a highly fluorescent naphthalimide dye. Cell 14: 741-759.

Stuart, A. E., A. J. Hudspeth, and Z. W. Hall (1974) Vital staining of specific monoamine-containing cells in the leech central nervous system. Cell Tissue Res. 153: 55-61.

Yamada, K. M., B. S. Spooner, and N. K. Wessells (1970) Axon growth: Roles of microfilaments and microtubules. Proc. Natl. Acad. Sci. USA 66: 1206-1212. 